\title{
FASE INICIAL DA PANDEMIA DA COVID-19 EM MATO GROSSO: DISTRIBUIÇÃO ESPACIAL E AVALIAÇÃO
}

\section{INITIAL PHASE OF THE COVID-19 PANDEMIC IN MATO GROSSO: SPATIAL DISTRIBUTION AND EVALUATION}

\author{
Diogo Marcelo Delben Ferreira de Lima \\ Doutorando em Geografia (USP) \\ Departamento de Geografia \\ Universidade Federal de Mato Grosso \\ diogomdelben@gmail.com
}

Marcia Alves Soares da Silva Doutora, Departamento de Geografia Universidade Federal de Mato Grosso marciaalvesgeo@gmail.com

Emerson Soares dos Santos Doutor, Departamento de Geografia Programas de Pós-Graduação em Geografia e Saúde Coletiva Universidade Federal de Mato Grosso emersonbrasileiro@gmail.com

\section{RESUMO}

Este estudo visa a apresentar a situação da fase inicial da pandemia da COVID-19 em Mato Grosso e avaliar a atuação do poder público. Trata-se de estudo retrospectivo descritivo em que são utilizados dados secundários obtidos em diversas fontes oficiais. Mato Grosso apresentava até o início do mês de maio de 2020 ritmo lento de crescimento do número de casos da COVID-19. A doença se concentrava nas cidades-polo e com pouca dispersão para as cidades vizinhas. O estado apresenta razoável estrutura hospitalar, porém com graves discrepâncias regionais. O conhecimento sobre a disseminação da COVID-19 mostra que as medidas de isolamento e distanciamento social foram importantes para frear o rápido crescimento da pandemia e que outras estratégias de combate à pandemia devem estar apoiadas em pesquisas acadêmicas e científicas e em levantamentos, análises e planos de atuação dos governos com a participação de atores sociais e da população. Acreditamos que, com a flexibilização das medidas de isolamento e intensificação dos fluxos entre as cidades do estado, a rede urbana terá papel fundamental na difusão espacial da doença e disseminação do vírus. Dessa maneira, as teorias e técnicas geográficas de análise urbano-regional serão imprescindíveis para melhor entendimento e elaboração de estratégias para contenção da COVID-19.

Palavras-chave: Organização Regional. Serviço de Saúde. Isolamento social.

\begin{abstract}
This study aims to present the status of the initial phase of the COVID-19 pandemic in Mato Grosso and evaluate government performance. This is a retrospective, descriptive study using secondary data obtained from several official sources. Until the beginning of May 2020, Mato Grosso had a slow growth rate in the number of cases of COVID-19. The disease was concentrated in the main cities, and there was still no diffusion to neighboring cities. The state holds modest hospital infrastructure, but with severe inequalities among regions. Knowledge about the spread of COVID-19 indicates that isolation measures and social distancing were important to stop the pandemic's rapid growth. Other strategies must be supported by academic and scientific studies and surveys, in addition to data collection, reports, and performance plans proposed by the government with the participation of social actors and the population. As isolation measures soften and the flow between cities in the state increases, we believe that the urban population will play a fundamental role in the
\end{abstract}

Recebido em: 10/05/2020

Aceito para publicação em: 02/06/2020. 
spatial spread of the disease and the virus. Thus, geographic theories and techniques of regional analysis will be essential for better understanding and elaboration of strategies to control COVID-19.

Keywords: Regional Organization. Health Service. Social isolation.

\section{INTRODUÇÃO}

Não estão definidas as causas e o momento exato do aparecimento da COVID-19 na China, mas os estudos em andamento atestam que os primeiros casos do vírus foram registrados entre novembro e dezembro de 2019 na cidade de Wuhan, capital da província de Hubei. Fora da Ásia, os primeiros casos foram registrados nos meses de janeiro e fevereiro do ano de 2020, e, no Brasil, o primeiro caso de COVID-19 -19 foi notificado em São Paulo no dia 25/02/2020. Após o primeiro registro em fevereiro, não tardou o crescimento do número de casos suspeitos e confirmados no país, incluindo óbitos pela doença. Conforme os dados do Ministério da Saúde (BRASIL, 2020), a COVID-19 atingiu todos os estados da federação e já tem ocasionado número significativo de óbitos.

Desde o primeiro caso confirmado da COVID-19 no estado de Mato Grosso, em 20 de março de 2020, o número de pessoas infectadas no estado tem aumentado rapidamente. Até 7 de maio de 2020, foram notificados 1.100 casos de Síndrome Respiratória Aguda Grave (SRAG) (SES-MT, 2020) e 420 casos confirmados da COVID-19, distribuídos em 36 dos 141 municípios. A idade média é de 42,5 anos e $55,5 \%$ dos casos eram do sexo feminino. A taxa de letalidade da COVID-19, a partir dos dados oficiais do estado, é de 3,3\%, ultrapassando em muito o número de óbitos registrados por SRAG no estado no mesmo período de 2019, que era de apenas $1 \%$ (SVS-MS, 2020). Estima-se, no entanto, que os dados oficiais sobre a disseminação do vírus estejam subestimados.

Do ponto de vista da dinâmica espacial, o processo de dispersão das doenças infectocontagiosas ocorre de duas maneiras: 1- Difusão Hierárquica e 2- Difusão por Contágio (CLIFF et al, 1981). A fase inicial da dispersão é caracterizada pela difusão hierárquica, que é extremamente dependente da forma de estruturação da rede urbana (CÂNDIDO et al, 2020 apud SPOSITO e GUIMARÃES, 2020), o que torna imperativo a identificação e monitoramento dos principais nós (cidades) e fios (malha viária) desta rede. Em nível nacional, o sistema Monitora COVID-19 (FIOCRUZ, 2020) já identificou algumas das principais rotas de difusão espacial da doença. A segunda fase da dispersão é dada pela difusão por contágio, processo em que as relações interpessoais nos níveis locais e características sociodemográficas tornam-se os fatores mais importantes no processo de disseminação do vírus, sendo que no perímetro urbano a difusão e distribuição dos casos ocorre de maneira desigual, como visto em Nova York, nos Estado Unidos (BORJAS, 2020), em Salvador (SILVA et al., 2020) e na cidade do Rio de Janeiro (CAVALCANTE; ABREU, 2020).

O objetivo deste estudo é descrever a distribuição espacial da ocorrência da COVID-19 em Mato Grosso na fase inicial da pandemia no estado no ano de 2020. São utilizados dados secundários provenientes da Secretaria de Estado de Saúde de Mato Grosso, disponibilizados através de Boletins Informativos publicados diariamente pelo órgão. Esses dados subsidiaram a elaboração de mapas temáticos da ocorrência de casos para os municípios do estado, e para a criação de gráficos sobre a sua evolução temporal. Os dados são agregados por Semana Epidemiológica, o que diminui eventuais flutuações ocasionadas por motivos como atraso da divulgação e sistematização dos resultados dos testes de infecção por Coronavírus.

\section{ESPACIALIZAÇÃO DA COVID-19 EM MATO GROSSO}

A cidade de Cuiabá, sendo a capital do estado, é a principal cidade de conexão (terrestre e aérea) com outras capitais e os seus estados. Nesse contexto, o vírus alastrou-se no território utilizando-se da rede urbano-regional do estado, possibilitado em função da posição geográfica e das funções que Cuiabá exerce (política, econômica, urbana). Com efeito, o vírus chegou a Mato Grosso e ao Brasil (e a outros locais) pela rede mundial de cidades, mas a partir daí a COVID-19 impôs a sua própria espacialidade, um comportamento territorial muito próprio que assimila fatores geográficos, demográficos e socioambientais, sem ser dependente do último, e que reproduz de forma agravada as desigualdades socioespaciais. 
Desde o final de fevereiro de 2020, o Governo de Mato Grosso vem monitorando os casos suspeitos da COVID-19, estes distribuídos em diversos municípios e regiões do estado. Depois do primeiro caso confirmado no país, Mato Grosso demorou mais de três semanas para ter o primeiro caso confirmado da COVID-19, uma pessoa residente em Cuiabá, notificado pela Secretaria de Estado de Saúde (SES-MT) em 20 de março. Levantamentos do Ministério da Saúde (BRASIL, 2020), apontados nos boletins epidemiológicos, informam que o estado de Mato Grosso é um dos entes da federação com as menores taxas de incidência e de letalidade do vírus. Mato Grosso encontra-se em fase pandêmica menos avançada que os demais estados do país, mas isso não significa que o estado é uma referência de combate ao Coronavírus, nem assegura que não terá um surto da doença no seu território.

Em 23 de março, foi decretada a situação de emergência por 90 dias no estado e consolidado um conjunto rigoroso de medidas contra a COVID-19, cabendo destacar: i) suspensão dos serviços públicos não essenciais na administração pública; ii) suspensão das atividades escolares nas redes de ensino pública e privada (federal, estadual e municipal); iii) suspensão de eventos públicos e proibição de aglomerações; iv) limitação na circulação de transporte público coletivo intermunicipal; v) recomendação e adoção de protocolos para o funcionamento de estabelecimentos comerciais (farmácias, supermercados e outros) e fiscalização sanitária; vi) proibição de funcionamento de estabelecimentos comerciais e industriais não essenciais; vii) obrigatoriedade da observância de medidas de prevenção individual e do cumprimento de normas médicas e sanitárias nos casos suspeitos e confirmados de COVID-19. Em Cuiabá e em vários municípios do interior do estado foram adotadas essas medidas, mais tarde editadas e promulgadas na legislação municipal. A política de prevenção ao COVID-19 e o distanciamento social influenciaram diretamente o ritmo de contaminação e o surgimento de casos novos em Mato Grosso.

Considerando o crescimento dos casos confirmados e de óbitos por COVID-19 em Mato Grosso, é possível afirmar que o vírus está circulando e afetando cada vez mais um número maior de pessoas (Figura 1), embora os óbitos aumentem lentamente. Casos da COVID-19 foram registrados no aglomerado urbano Cuiabá e Várzea Grande e atingiu o interior do estado. Importante observar que na primeira fase pandêmica não há notificações da doença em municípios menores que compõem a Região Metropolitana do Vale do Rio Cuiabá (RMVRC): Acorizal, Chapada dos Guimarães, Santo Antonio do Leverger e Nossa Senhora do Livramento, e o seu entorno metropolitano: Barão de Melgaço, Jangada, Nobres, Nova Brasilândia, Planalto da Serra, Poconé e Rosário Oeste.

Figura 1 - Casos novos de Covid-19 por Semana Epidemiológica em Mato Grosso

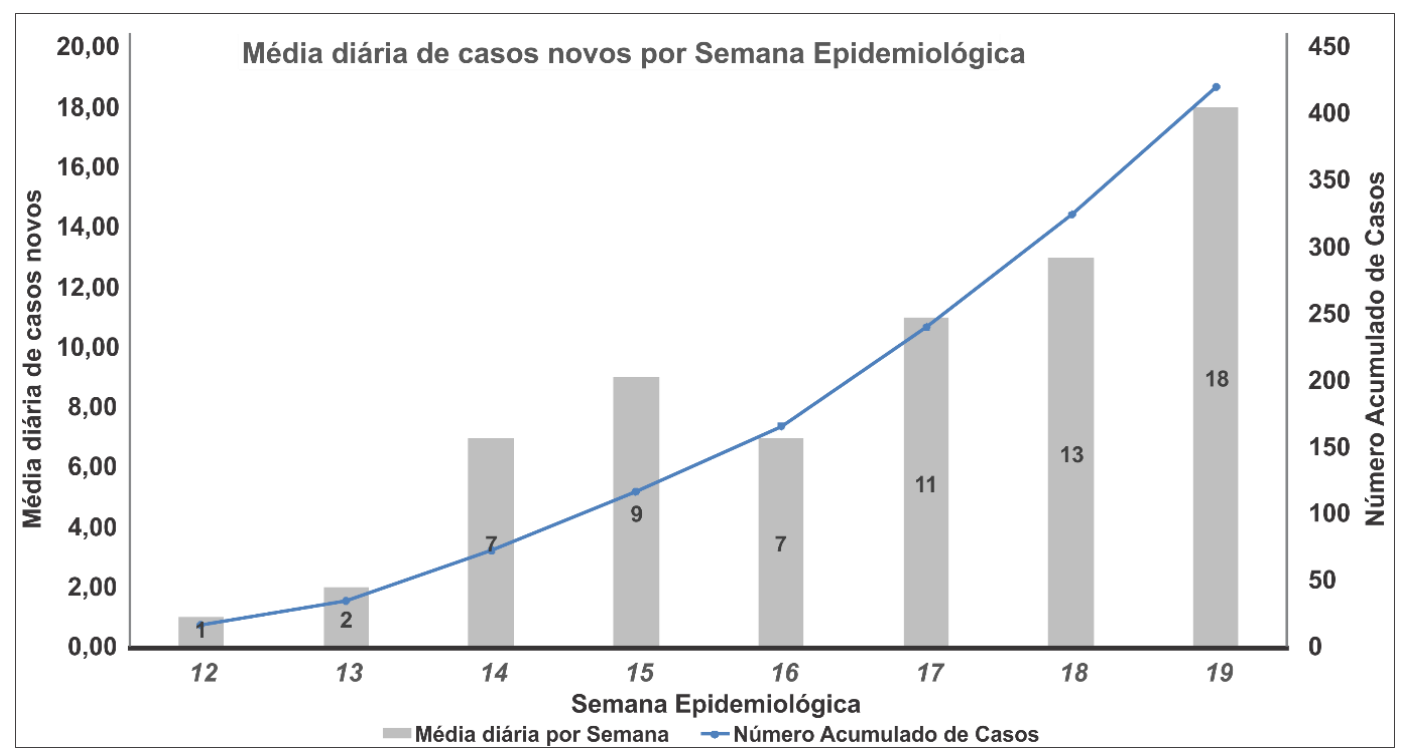

Fonte dos dados: SES-MT 
A inexistência de um espaço metropolitano contínuo (urbanizado e conurbado) contribui para que o vírus não se espalhe facilmente pelos territórios adjacentes do núcleo metropolitano. No entanto, a maior circulação de pessoas infectadas na RMVRC e no seu entorno tende a aumentar o risco de contágio, consequentemente, os fluxos de pessoas na metrópole mato-grossense são potencialmente prejudiciais ao controle sanitário. A metropolização regional em torno de Cuiabá e as concentrações populacionais e econômicas, estudadas com profundidade por Vilarinho Neto (2009), podem ser fatores importantes no combate à pandemia.

Para Higa, Romancini e Nunes (2001), a ocupação territorial e o desenvolvimento da agricultura moderna favoreceram o surgimento de cidades no interior do estado, e a desconcentração produtiva e econômica, o crescimento da agroindústria e do setor terciário (comércio e prestação de serviços) e a descentralização político-administrativa em Mato Grosso corroboraram para a formação e a estruturação dos polos regionais, sendo eles: Rondonópolis (Sudeste), Sinop (Centro-Norte), Cáceres (Sudoeste), Tangará da Serra (Oeste), Sorriso (Centro), Barra do Garças (Leste), Alta Floresta (Norte) e Juara (Noroeste).

Dito isso, a rede urbano-regional de Mato Grosso, mesmo tendo a RMVRC como centro dinâmico, não é tão dependente das funções da metrópole mato-grossense, sobretudo da capital. A existência de uma rede urbano-regional com uma região metropolitana não hegemônica, com média intensidade socioespacial no território e com polos regionais relativamente autônomos, dotados de articulações e influências sobre o seu entorno, dificulta a identificação prévia de padrões geográficos para dispersão da COVID-19.

A diferenciação interna do espaço territorial mato-grossense evidencia que as cidades e as regiões do estado possuem dinâmicas demográficas, sociais, econômicas e políticas próprias. Não obstante, a infraestrutura urbana e social, as políticas públicas, as ações estatais e privadas de prevenção e contenção da COVID-19, que também constituem fatores dessa diferenciação territorial, podem atenuar ou agravar a transmissão do vírus e dos seus efeitos na população e na sociedade. As conjunturas demográficas e médico-sanitárias do estado e dos seus municípios devem ser analisadas atentamente, cumprindo verificar os efeitos das medidas de prevenção e contenção da COVID-19 na chamada primeira fase pandêmica, isto é, transmissão local e comunitária do vírus. Esse entendimento sobre a espacialização do vírus no estado deve contemplar o crescimento e a distribuição de casos nos municípios (Figura 2).

De certa maneira, Mato Grosso pode ter adotado um "distanciamento social precoce", isto é, iniciou medidas preventivas combinadas com restrições às atividades econômicas antes mesmo de ter um número expressivo de casos confirmados da COVID-19. Com monitoramento dos casos pela SES-MT foi possível assegurar um quadro geral de registros de transmissão do vírus sem crescimento significativo das taxas de incidência e/ou de letalidade da COVID-19. Logo, Mato Grosso está distante da realidade dos principais estados e capitais atingidos pelo vírus (até a data de 9 de maio de 2020 informava 502 casos confirmados), mas está inserido na Amazônia Legal e tem características semelhantes aos estados do Amazonas e do Pará, que estão entrando em surto pandêmico e vendo colapsar a saúde pública e os serviços funerários. Então, existe um "alerta amazônico" que não pode ser ignorado no sentido de que a situação pode piorar, além de que não se pode negar a gravidade dos fatos já conhecidos.

Apenas uma análise espacializada e contextualizada da COVID-19, acompanhada de prognósticos, de planejamento e de monitoramento das ações contra o vírus, pode servir para orientar os governos e a sociedade. Uma dessas análises foi realizada por pesquisadores do Departamento de Geografia e do Instituto de Saúde Coletiva, ambos da Universidade Federal de Mato Grosso (UFMT), que abordaram a disponibilidade de leitos e de equipamentos para tratamento dos infectados por COVID19 no estado a partir de cenários espaço-temporais com quadros diversos de níveis de infecção. De acordo com Santos et al (2020), a capacidade de atendimento da população infectada é diferenciada conforme a região de saúde no estado, logo, a política de saúde deve implementar ações regionalizadas de modo a equalizar o acesso, corrigir as desigualdades, otimizar a utilização da infraestrutura e dos recursos técnicos, humanos e financeiros, e reduzir os danos por COVID-19. 
Figura 2 - Distribuição espacial e evolução da COVID-19 em Mato Grosso

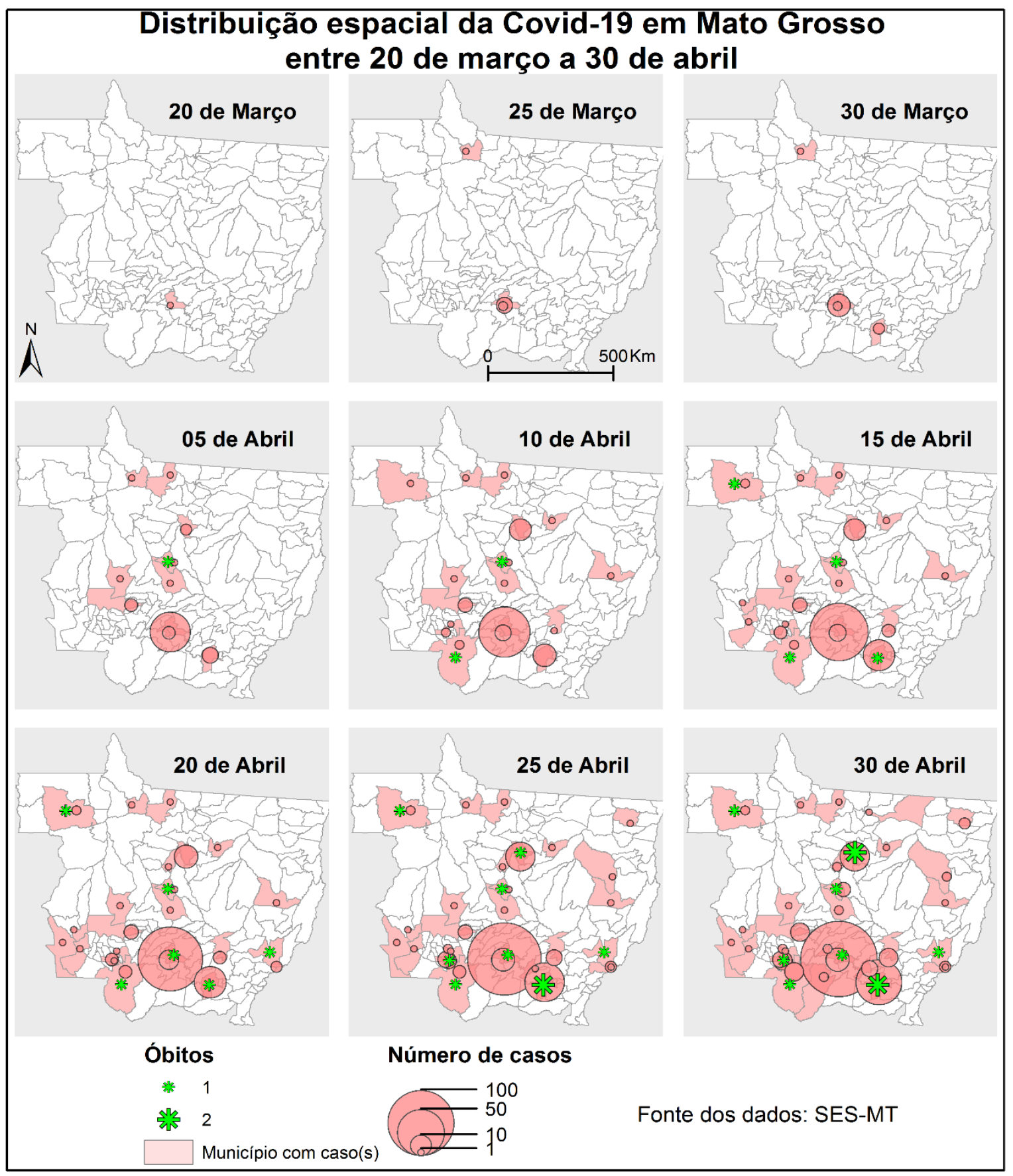

Embora existam pesquisas acadêmicas e científicas, planejamento e gestão da saúde pública e da pandemia da COVID-19 que são acompanhados e fiscalizados por diversos órgãos de controle (Tribunal de Contas, Poder Legislativo e Ministério Público), ainda faltam mais instrumentos para conhecimento da realidade social para o enfrentamento do problema no país e no estado de Mato Grosso, principalmente na escala intraurbana. Isso implica dizer que o momento atual exige governança, diálogo político-social, coordenação das ações público-privadas e implementação de decisões acertadas para fortalecimento do sistema de saúde, proteção da saúde das pessoas, redução e controle da transmissão do vírus, ações relevantes para o retorno gradual e seguro das atividades sociais e econômicas. 
Mato Grosso tem um Plano de Contingência Estadual para Infecção Humana pelo Novo Coronavírus - COVID-19 (MATO GROSSO, 2020) que orienta a atuação dos órgãos governamentais da saúde e define diretrizes para organização dos sistemas municipais de saúde. Esse Plano prevê e descreve a ocorrência de cenários de risco e de contágio, e estabelece as medidas adequadas a serem implantadas, as quais já possuem protocolos no âmbito da atenção básica, secundária e hospitalar. $\mathrm{O}$ Plano foi atualizado recentemente e apresenta a situação dos leitos clínicos e de Unidades de Terapia Intensiva (UTI) (Figura 3) para tratamento dos doentes, contudo, o documento não informa a disponibilidade de profissionais da área da saúde nas unidades, de equipamentos de proteção individual e de respiradores pulmonares. Esse levantamento mostra-se parcial e incompleto, pois também ignora a demanda regular na rede do Sistema Único de Saúde (SUS) do estado e estabelece medidas (reserva de leitos) que prejudicam o atendimento aos demais doentes (não afetados pela COVID-19).

Para o Governo Estadual, a situação pandêmica está sob controle e todas as medidas necessárias para ampliação e melhoria da oferta dos serviços de saúde com foco no tratamento e na recuperação dos pacientes infectados por COVID-19 estão sendo tomadas. O estado espera contar com a infraestrutura de leitos clínicos e UTIs e afirma se comprometer com a contratação de profissionais, aquisição de remédios, materiais e equipamentos, e realização de outros investimentos e despesas necessárias. A Rede Pública conta com 326 leitos UTI e 947 leitos hospitalares clínicos. A posição do Governo Estadual tem sido reafirmar a capacidade do sistema de saúde de suportar o aumento expressivo da demanda, buscando a retomada da economia de forma gradual e progressiva. Tal retomada acontece mediante a redução das restrições às atividades econômicas e produtivas, o funcionamento em tempo parcial dos órgãos públicos, a reabertura de alguns espaços e estabelecimentos desde que observadas normas e controles sanitários, a permissão da circulação de pessoas pelos sistemas de transporte público municipal e intermunicipal, e o retorno programado às aulas nas redes pública e privada de ensino.

Figura 3 - Leitos exclusivos para COVID-19 inseridos no Plano de Contingência Estadual para Infecção Humana pelo Novo Coronavírus - COVID-19.

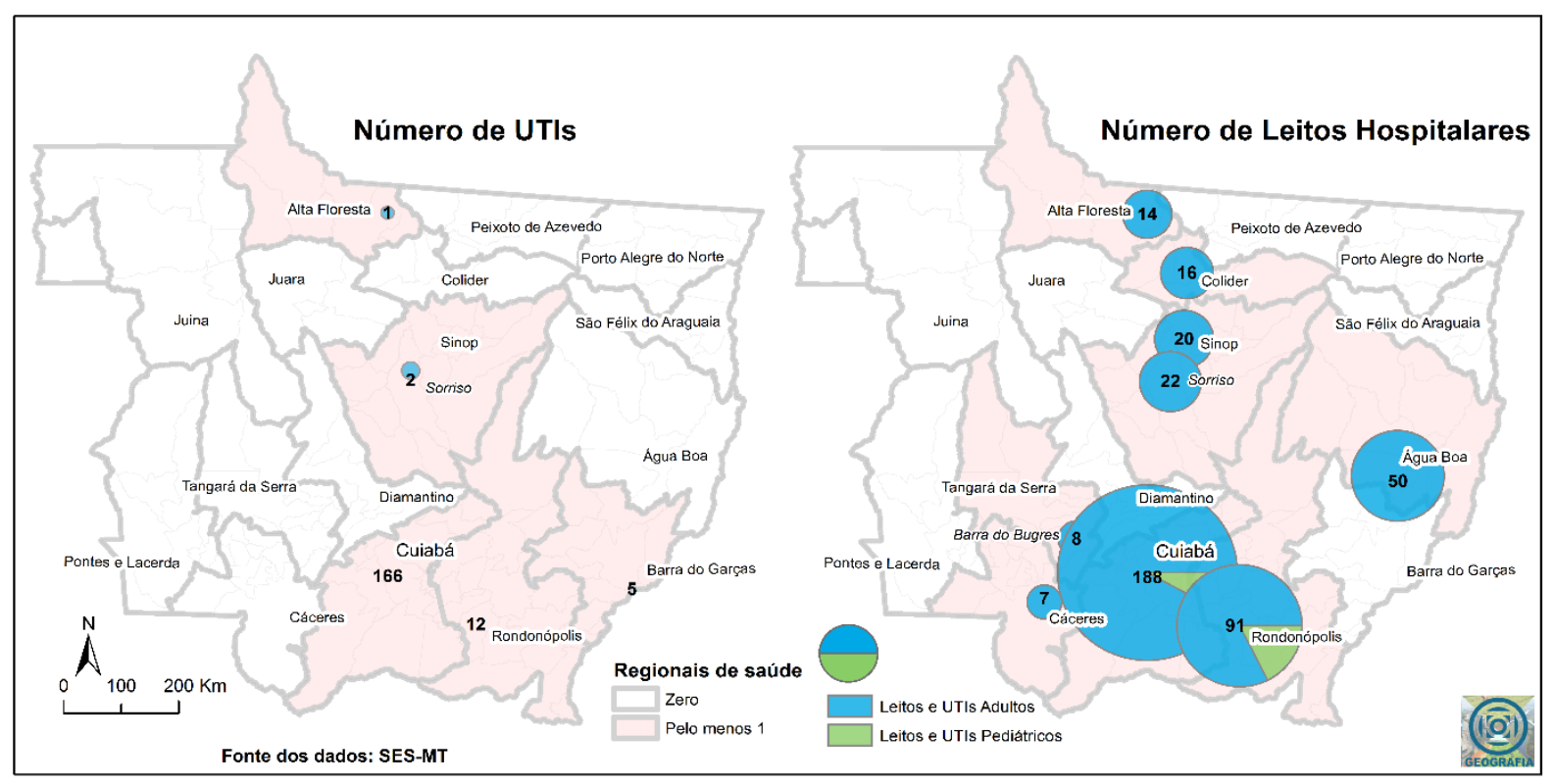

Fonte: SES-MT, 2020.

É certo que o distanciamento social foi responsável pela menor velocidade da transmissão da doença no estado, porém as medidas preventivas estão sendo flexibilizadas ou descumpridas em várias localidades, o que claramente ocorre em Mato Grosso. A presença de pessoas entre os dias 20 de março e 2 de maio aumentou em lojas e recreação [-70\% para $-40 \%]$, farmácias [-36\% para -2], 
parques [52\% para $-12 \%]$, pontos de ônibus [-52\% para $-37 \%$ ] e locais de trabalho [-29\% para $-18 \%]$, e diminuiu em áreas residenciais [11\% para $7 \%$ ] (Figura 4). Devido ao agravamento da crise, a pressão de setores econômicos, de grupos de opinião pró-Governo Federal e a situação social do trabalhador, estados e municípios estão tomando providências para o retorno das atividades econômicas e para a volta da população às ruas. Os efeitos positivos das medidas preventivas e restritivas, de modo especial a redução do ritmo de crescimento da COVID-19 e o retardamento do pico da doença estão sendo ignorados. Fatalmente, o país e as unidades da federação irão sair da "quarentena" sem ter atingido o pico da curva de infecção.

Figura 4 - Mobilidade das pessoas portadoras de telefone celular em Mato Grosso, a partir do dia 21 de março de 2020, dia do primeiro caso registrado no Estado.

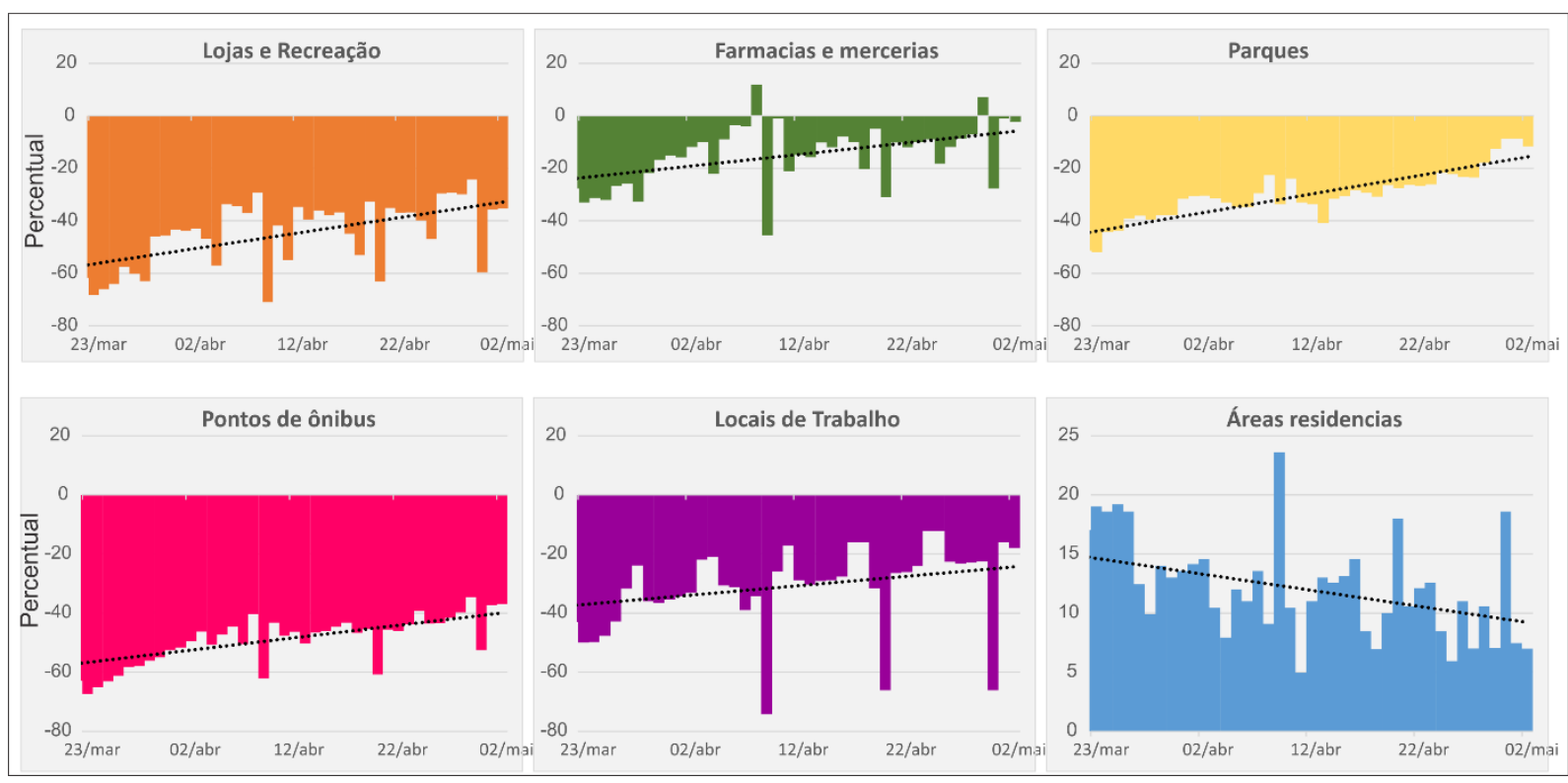

Fonte: Google Mobility Report

O quadro pandêmico estadual revela-se a cada dia mais preocupante. Com o crescimento do número de exames e testes rápidos da COVID-19, nota-se que o contingente de infectados é muito maior do que o conhecido e que o vírus está espalhado por muitos municípios e localidades. A partir de 22 de abril, os boletins da SES-MT já apontavam o descontrole da transmissão da COVID-19 no estado e o crescimento muito acelerado de novos casos da COVID-19. Em menos de uma semana, de 20 a 25 de abril, Mato Grosso partiu de 181 casos confirmados da COVID-19 para 247 casos acumulados do vírus (SES-MT, 2020). Conforme o Ministério da Saúde (BRASIL, 2020), esse período teve 73 casos novos da COVID-19 no estado, um aumento em torno de $36 \%$.

Em 22 de abril, o Governo de Mato Grosso implementou "nova" política de prevenção e contenção da COVID-19 baseada no desenvolvimento da pandemia no estado. O estado decidiu repactuar as medidas de combate ao Coronavírus e reforçar a competências dos municípios no que diz respeito à adoção das medidas adequadas às realidades locais, mas o ato administrativo implicou o abandono da estratégia de confinamento social.

Sem polemizar a respeito da compreensão governamental sobre a dimensão da pandemia da COVID-19 e da efetividade das políticas e ações governamentais, é importante ter em conta que o Governo Estadual substituiu o paradigma de abordagem da pandemia de preventivo para reativo. $\mathrm{O}$ estado adota uma visão que defende a aptidão da gestão da saúde pública e a mecanismo de monitoramento dos casos da COVID-19 voltado à intervenção governamental. Além disso, tem decidido atuar numa lógica gerencial que supervaloriza as competências, estruturas e resultados, e assume riscos e danos (graves, desnecessários e/ou com justificativas questionáveis). Os comitês multissetoriais, os painéis e os mapeamentos da COVID-19 são fundamentais para a implementação 
das políticas e das ações governamentais; no entanto, tais instâncias e recursos possuem limitações e precisam explorar outras perspectivas políticas e sociais.

Com o agravamento da crise pandêmica e social, a "nova" política de enfrentamento da COVID-19 precisará ainda mais da coordenação das ações governamentais nas diversas esferas (federal, estadual e municipal) e da elaboração de planos estaduais e municipais atentos às diferentes situações pandêmicas e às dimensões demográficas, urbanas e sociais nos territórios. A construção desse sistema de enfrentamento da COVID-19 terá que acompanhar a disseminação do vírus e as interações socioespaciais, revelando as escalas de ação, experiências possíveis e outras vivências num contexto tão difícil. O conhecimento sobre a COVID-19 não é uma prerrogativa do estado ou de qualquer outra instituição, nem se limita a um conjunto de dados e informações expostos em quadros, tabelas, gráficos e mapas, ou organizados em textos, relatórios, boletins epidemiológicos, notas técnicas e artigos. Esse conhecimento é uma relação e é uma construção coletiva. Seguramente, o problema da COVID-19 exige um pacto social e mudanças significativas nos arranjos governamentais e nas estruturas sociais.

Antes de iniciar qualquer medida de flexibilização e relaxamento das normas em vigor, o poder público deve assegurar o bom funcionamento da atenção básica de saúde (a triagem, a realização de exames para casos suspeitos e acompanhamento de infectados), a reorganização da rede de saúde de média e alta complexidade (disponibilidade de remédios, equipamentos e de unidades para tratamento médico-hospitalar). Sem essas medidas e com a disseminação do vírus nas cidades, a pandemia se agravará e causará danos irreparáveis. Uma mudança brusca e equivocada na política de prevenção e contenção da COVID-19 fará com que o estado e os seus municípios entrem em nova fase pandêmica: aceleração descontrolada dos casos da doença, impossibilidade de acompanhamento efetivo da transmissão do vírus e de intervenção na saúde pública. Portanto, exigese atenção diária ao fenômeno e sua dinâmica, levando em consideração as singularidades locais e regionais, bem como elementos preexistentes que certamente podem afetar na situação da pandemia, como as desigualdades socioespaciais e as populações em situação de vulnerabilidade.

\section{CONSIDERAÇÕES FINAIS}

Considerando o contexto atual de Mato Grosso, depreende-se que os problemas apontados de ordem político-administrativa no sistema estadual de saúde devem ser acompanhados e reavaliados constantemente para tomada de decisões acertadas em prol da saúde pública. A estrutura (física, técnica, logística, humana e financeira) e a organização dos serviços de saúde precisam estar preparadas, de fato, para o momento do surto pandêmico, que não tardará a acontecer caso consideremos a trajetória já observada em outras localidades do Brasil e do mundo. O conhecimento sobre a disseminação da COVID-19 mostra que as medidas preventivas foram importantes para frear o rápido crescimento da pandemia e que outras estratégias de combate devem estar apoiadas em pesquisas acadêmicas e científicas e em levantamentos, análises e planos de atuação dos governos com a participação de atores sociais e da população. Diante do agravamento da situação pandêmica e social e da flexibilização da "quarentena", outras abordagens e perspectivas devem ser exploradas pelos agentes públicos e atores sociais para proposição de projetos e de iniciativas adequadas à redução dos efeitos negativos da COVID-19 na sociedade e na economia. Acreditamos que, com a flexibilização das medidas de isolamento e intensificação dos fluxos entre as cidades do estado, a rede urbana terá papel fundamental na difusão espacial da doença e disseminação do vírus. Desta maneira, as teorias e técnicas geográficas de análise regional serão imprescindíveis para melhor entendimento e elaboração de estratégias para contenção da COVID-19

\section{REFERÊNCIAS}

BORJAS, G. J. Demographic Determinants of Testing Incidence and COVID-19 Infections in New York City Neighborhoods. NBER Working Paper No. 26952. Cambridge, 2020. https://doi.org/10.3386/w26952

BRASIL, MINISTÉRIO DA SAÚDE. Boletim epidemiológico 09. COE-COVID 19. 11 de abril de 2020. Disponível em https://portalarquivos.saude.gov.br/images/pdf/2020/April/12/2020-04-11-BE9Boletim-do-COE.pdf. Acesso em 12.04.2020.

BRASIL, MINISTÉRIO DA SAÚDE. Boletim epidemiológico 13. COE-COVID 19. 20 de abril de 2020. https://portalarquivos.saude.gov.br/images/pdf/2020/April/21/BE13---Boletim-do-COE.pdf. 
BRASIL, MINISTÉRIO DA SAÚDE. Coronavírus - Brasil. Disponível em: https://covid.saude.gov.br. Acesso em 25.04.2020.

CAVALCANTE, J. R.; ABREU, A. J. L. COVID-19 in Rio de Janeiro municipality: spatial distribution of the first deaths and cases confirmed. Scielo preprints - Seção Saúde 2020.

CLIFF, A. D. et al. Spatial Diffusion: an historical geography of epidemics in an island comunity. Cambridge: Cambridge University Press, 1981.

FIOCRUZ-MONITORA COVID-19. Tendências atuais da pandemia de Covid-19: Interiorização e aceleração da transmissão em alguns estados Nota Técnica 17 de abril de 2020.

GOOGLE LLC "Google COVID-19 Community Mobility Reports". www.google.com/covid19/mobility/ Acesso em 02.05.2020.

HIGA, T. C. C. de; ROMANCINI, S. R; NUNES, M. A. Mato Grosso: dinâmica urbano-regional do Estado. In: PEREIRA, Rafael Henrique Moraes. FURTADO, Bernardo Alves. Dinâmica urbanoregional: rede urbana e suas interfaces. Brasília. IPEA, 2011.

MATO GROSSO. Plano de contingência estadual para infeccção humana pelo novo Coronavírus - CoVID-19. Disponível em: http://www.saude.mt.gov.br/informe/581. Acesso em 24.04.2020.

SANTOS, E. S; ZEILHOFER, P.; MURARO, A. P.. Análise de demanda adicional de leitos hospitalares gerais, UTI e equipamentos de ventilação assistida em Mato Grosso em função da pandemia de COVID-19: impactos regionais. Nota Técnica. IGHD/ISC - UFMT: Cuiabá, 2020. < http://geografiaufmt.com.br/index.php/pt-br/component/sppagebuilder/?view=page\&id=5>

SES-MT, SECRETARIA DE ESTADO DE SAÚDE DE MT. Boletim informativo $\mathbf{n}{ }^{\circ} \mathbf{6 0}$. Situação epidemiológica SRAG e COVID-19. Disponível em: http://www.saude.mt.gov.br/informe/584. Acesso em 07.05.2020.

SES-MT, SECRETARIA DE ESTADO DE SAÚDE DE MT. Boletim informativo $\mathbf{n}{ }^{\circ}$ 48. Situação epidemiológica SRAG e COVID-19. Disponível em: http://www.saude.mt.gov.br/informe/584. Acesso em 25.04.2020.

SILVA, R.J.; SILVA, K.B.; MATTOS, J. B. Nota técnica. Análise espacial sobre a dispersão da COVID-19 no estado da Bahia. Disponível em: https://preprints.scielo.org/index.php/scielo/preprint/view/39/89.

SPOSITO, M. E. B; GUIMARÃES, R. B. Por que a circulação de pessoas tem peso na difusão da pandemia: Difusão da Covid-19 no país segue modelo relacionado a interações espaciais na rede urbana. UNESP 2020.

SVS-MS. Influenza: Monitoramento até a Semana Epidemiológica 16 de 2019. Publicado em 25 de abril de 2020. Disponível em: https://www.saude.gov.br/images/pdf/2019/abril/30/informeinfluenza-se16-25abr19c.pdf

VILARINHO NETO, C. S. A metropolização regional, formação e consolidação da rede urbana do estado de Mato Grosso. Cuiabá. Ed. UFMT, 2009. 